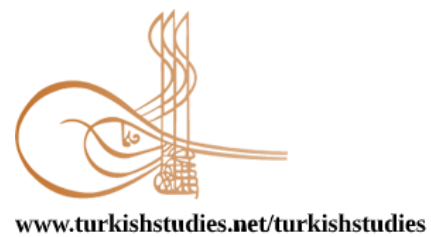

Turkish Studies

Research Article / Araștırma Makalesi

\title{
COVID-19 Salgını Bir Gıda Güvenliği Tehlikesi Midir?
}

\author{
Is the COVID-19 Pandemic a Food Safety Hazard?
}

\author{
Yasin Akkemik $^{*}$ - Ahmet Güner ${ }^{* *}$
}

\begin{abstract}
COVID-19, also known as the new type of coronavirus disease, is a respiratory system infection that occurs in Wuhan, China. Infection is caused by severe acute respiratory syndrome coronavirus 2 (SARSCoV-2) virus. It has become a global epidemic that affects the whole world today. June 13, 2020 at 8 million people across the world COVID-19 cases and 432.892 deaths, in Turkey 175.677 cases, 4.792 deaths occurred. Public safety guidelines are followed all over the world to stop the spread of COVID-19 and protect public health. Despite the fact that COVID-19 is an invasive factor in the respiratory tract, it is followed with concern by consumers, as it also endangers food safety and can be transmitted through foods. Despite the great suspicion and fear of consumers whether COVID-19, which has a highly contagious and lethal effect, will infect people with food purchased from markets or restaurants, there is no evidence to date that the agent is transmitted through food and has caused the disease as a result of consuming contaminated foods. However, it is emphasized that people who are in the food production chain and carry the SARS-CoV2 virus without symptoms can infect food. Among the measures applied to prevent the agent from contaminating the food chain and preventing it from being transmitted to humans; There are measures implemented in the form of washing the hands of people working in the food chain regularly, providing continuous training to raise the awareness of the employees, maintaining the hygiene and sanitation practices effectively in the enterprises, separating raw and cooked foods to prevent cross contamination. In addition, the consumption of packaged foods, fruits and vegetables and ready-to-eat foods for a while after purchasing is among the basic measures applied. In this review, the source of the COVID-19 infection, its epidemiology, its transmission and its relationship with food safety are given, and the role of the agent among foodborne infections, contamination from food surfaces, its effectiveness on food processing and food packaging.
\end{abstract}

Structured Abstract: The highly contagious new type of coronavirus infection (COVID-19) was identified in December 2019 and was declared an epidemic (pandemic) by the World Health Organization (WHO) on March 11, 2020. The first infections occurred at the Huanan Seafood Market in Wuhan, China. In the sequencing study, it was reported that up to $96.2 \%$ similarity was observed in gene sequences between SARS-CoV-2 and bat coronavirus. As a result of the study, bats were reported to be possible sources of SARS-CoV-2.

\footnotetext{
* Öğretim Görevlisi, Selçuk Üniversitesi, Karapınar Aydoğanlar MYO, Gıda İşleme Bölümü

Lecturer, Selcuk University, Karapınar Aydoğanlar Vocational School, Food Processing Department

ORCID 0000-0002-9086-0324

yasinakkemik@selcuk.edu.tr

** Profesör Doktor, Selçuk Üniversitesi, Veteriner Fakültesi, Besin Hijyeni ve Teknolojisi Bölümü

Professor Doctor, Selcuk University, Faculty of Veterinary Medicine, Food Hygiene and Technology Department

ORCID 0000-0001-9661-555X

aguner@selcuk.edu.tr
}

Cite as/ Atıf: Akkemik, Y. \& Güner, A. (2020). Covid-19 salgını bir gıda güvenliği tehlikesi midir?. Turkish Studies, 15(4), 15-23. https://dx.doi.org/10.7827/TurkishStudies.44409

Received/Geliș: 22 June/Haziran 2020

Accepted/Kabul: 26 August/Ağustos 2020

Checked by plagiarism software

Copyright (C) MDE, Turkey

Published/Yayın: 30 August/Ağustos 2020

CC BY-NC 4.0 
No treatment or vaccine has yet been developed for COVID-19 disease. Therefore, the scientific community and official institutions and organizations carry out various studies for the short and long-term management of current and future pandemic crises. The food industry and its stakeholders are also included in these studies. Because a serious pandemic that causes more than $25 \%$ reduction in the current workforce can compromise food security by causing significant food shortages worldwide. For this reason, all stakeholders should quickly identify critical threats and measures to be taken to prevent the conversion of existing hazards into major risks.

There are some important issues that the food industry should address in the new period. The most important of these is to make the concept of food safety even more important to prevent the virus from spreading in the food chain (among manufacturers, retailers and consumers). The other is the solution to the problems that may arise in food security due to the withdrawal of approximately one billion people in quarantine in their homes from food production. Another one is the elimination of the problems that may arise in the supply of these products in the market as a result of the increase in the demand for these products as consumers turn to healthier diets in order to strengthen their immune systems. In addition, it is necessary to ensure the sustainability of food systems in order to solve these issues and reduce the effects of future crises.

CoVs are zoonotic viruses transmitted from animals to humans. SARS is transmitted to humans by bats native to Asia and Africa, and MERS by camels. Given the similarity of SARS-CoV-2 to bat-associated SARS-CoV, bats are likely to be seen as reservoirs and infect humans. Some CoVs transmitted by anteater have a receptor binding domain (RBD) similar to SARS-CoV-2. Thus, it has been reported that anteater can be directly or indirectly effective in transmitting the virus to humans.

Infection in SARS-CoV-2, like flu and other respiratory system viruses, is in the form of transmission from person to person. The virus spreads through droplets of water that hang in the air and become invisible after the sick person sneezes or coughs. Anyone within an 1.8-meter radius of an infected person is at risk. Since the spread and genetic transmission of RNA viruses often takes place through respiratory and droplet, SARS-CoV-2 is expected to be less virulent through human-to-human transmission if necessary precautions are taken.

During food processing, it is possible for SARS-CoV-2 to contaminate the hands of operating personnel from contaminated surfaces. The person may be exposed to SARS-CoV-2 when he touches a contaminated surface or object and can then self-infect by oral, nasal, or optical means. Although some individuals are infected orally, SARS-CoV-2 is a highly 'sensitive' virus. In theory, swallowed SARS-CoV-2 is destroyed by stomach acid. It can be easily eliminated by washing hands with soap and / or using alcoholbased hand disinfectants. As a proactive approach, 4 steps of food safety (cleaning, separating, cooking and cooling) should be effectively implemented to prevent foodborne illnesses (including COVID-19).

Virus epidemiology is very complex. Coronaviruses can spread from animal reservoirs to human hosts. The exact mechanism for this contamination between species is not fully understood. However, in crowded environments where domestic or wild animals and humans are almost intertwined, infection from animals to humans occurs very often. The resulting data show that in addition to inhalation from droplets from coughing and sneezing, fecal-oral spread should be carefully controlled and monitored.

The safety of the food chain becomes even more important during epidemic periods around the world. It is very important that the cause of the outbreak is not contaminated by this chain and that the chain is not broken. The world-threatening COVID-19 disease is a disease caused by the passage of SARS-CoV-2 to people through breathing and contact. According to current studies, the transmission of this virus to food occurs by infected food workers who work in food establishments and show no symptoms but carry the virus. For this reason, those who work in the food chain should be made aware of all other food safety hazards, including COVID-19, and those who are sick should not be employed. In addition, employees should wear masks.

According to current studies, although there is no information about the infection of SARS-CoV-2 virus with food and food packaging, the possibility that infected people may come into contact with food and food packaging should be considered and personal hygiene should be provided for this purpose. Attention should be paid to routine food safety practices prior to consumption of foods. The most important application is that hands, mouth, nose or eyes should not be touched after touching any surface or food. Hands must be

Turkish Studies, 15(4) 
washed with soap and water for at least 20 seconds. Consumers also have great responsibilities in this process. Consumers should maintain social distance, wear a mask and pay attention to general hygiene rules when shopping for food. After the market shopping, the washable ones should be washed with soapy water and the non-washable ones should be used after waiting for a while in suitable environments. Foods that should be consumed by cooking should not be consumed raw or undercooked. Raw and baked products should not be handled and kept together to prevent cross contamination. Raw fruits and vegetables should be washed thoroughly with plenty of water and food cleaning brushes before consumption.

As a result, COVID-19 disease caused by SARS-CoV-2 poses a great risk for public health. Although there is no scientific data about the infection of this virus with the consumption of food, food producers and consumers should follow the hygiene rules more than ever and turn the hygiene rules into a routine process in their daily lives. Thus, it is thought that the concerns and thus the controversy about carrying this virus with food can be prevented.

Keywords: Food Safety, Food Security, Public Health, COVID-19, SARS-CoV-2, Pandemic

Öz: Çin'in Wuhan şehrinde ortaya çıkan ve yeni tip Koronavirüs hastalı̆̆ olarak da bilinen COVID-19 bir solunum sistemi enfeksiyonudur. Enfeksiyona şiddetli akut solunum yolu sendromu koronavirüsü 2 (SARS$\mathrm{CoV}-2)$ virüsü neden olmaktadır. Günümüzde tüm dünyayı etkisi altına alan küresel bir salgın haline gelmiştir. 13 Haziran 2020 tarihinde dünya genelinde 8 milyona yakın COVID-19 vakası ve 432.892 ölüm, Türkiye'de ise 175.677 vaka, 4.792 ölüm meydana gelmiştir. COVID-19'un yayılmasını durdurmak ve halk sağlığını korumak için tüm dünyada kamu güvenliği yönergeleri takip edilmektedir. COVID-19, solunum yolu organlarına invazyon gösteren bir etken olmasına rağmen, tüketiciler tarafindan gıda güvenliğini de tehlikeye attığı ve gıdalar ile de bulaşabileceği ihtimalinden dolayı endişe ile takip edilmektedir. Çok bulaşıcı ve öldürücü etkisi olan COVID-19'un marketlerden alınan gıdalarla veya restoranlardan evlere sipariş edilen yiyeceklerle insanları enfekte edip etmeyeceği yönünde tüketicilerdeki büyük şüphe ve korkuya rağmen, etkenin gıda yoluyla bulaştığına ve kontamine gıdaların tüketilmesi sonucunda hastalık yaptığına dair günümüze kadar herhangi bir kanıt bulunmamaktadır. Bununla birlikte, gıda üretim zincirinde yer alan ve semptom göstermeden SARS-Cov-2 virüsünü taşıyan kişilerce etkenin gıdalara bulaşabileceği üzerinde durulmaktadır. Gıda zincirinde çalışan kişilerin düzenli olarak ellerini yıkaması, çalışanların farkındalıklarının artırılması amacıyla sürekli eğitimlerin verilmesi, işletmelerde hijyen ve sanitasyon uygulamalarının etkin bir şekilde sürdürülmesi, çapraz kontaminasyonu önlemek için çiğ ve pişmiş gıdaların ayrılması şeklinde uygulanan önlemler, etkenin gıda zincirini kontamine etmesi ve insanlara bulaşmasının engellenmesi açısından uygulanan tedbirler arasında yer almaktadır. Ayrıca ambalajlı gıdaların, meyvesebzelerin ve tüketime hazır gıdaların satın alındıktan sonra bir süre bekletilerek tüketilmesi de uygulanan temel tedbirler arasındadır. Bu derleme ile COVID-19 enfeksiyonunun kaynağı, epidemiyolojisi, iletimi ve gıda güvenliği ile ilişkisi hakkında bilgi verilerek etkenin gıda kaynaklı enfeksiyonlar arasındaki yeri, gıda yüzeylerinden bulaşma durumu, gıda işleme ve gıda ambalajlama üzerindeki etkinliği açıklanmaktadır.

Anahtar Kelimeler: Gıda Güvenliği, Gıda Güvencesi, Halk Sağlığı, COVID-19, SARS-CoV-2, Pandemi

\section{Giriş}

Oldukça bulaşıcı yeni tip Koronavirüs enfeksiyonu (COVID-19), Aralık 2019'da tanımlanmış ve 11 Mart 2020'de Dünya Sağlık Örgütü (DSÖ) tarafından salgın hastalık (pandemi) olarak ilan edilmiştir (WHO, 2020a). İlk enfeksiyonlar Çin'in Wuhan kentindeki Huanan Deniz Ürünleri Market'inde ortaya çıkmıştır (Li et al., 2020). Yapılan sekanslama çalışmasında SARSCoV-2 ve yarasa koronavirüsü arasındaki gen dizilerinde \%96,2'ye kadar benzerlik görüldüğü bildirilmiştir. Çalışmanın sonucunda yarasaların SARS-CoV-2'nin muhtemel kaynağı olduğu bildirilmiştir (Zhou et al., 2020).

Salgının başladığı andan günümüze kadar geçen sürede sayılar hızla artmış ve 13 Haziran 2020 itibariyle 200'den fazla ülkede 7,9 milyon COVID-19 vakası ve 432,962 ölüm, Türkiye'de ise 175.677 vaka, 4.792 ölüm bildirilmiştir. COVID-19'un inkübasyon süresi, üç ayrı çalışmada 5.2, 5.1 ve 4 gün olarak bildirilmiştir (Bulut \& Kato, 2020; Li et al., 2020). Bununla birlikte, bu 
enfeksiyona yakalanmış 5 kişilik bir ailede inkübasyon süresinin 1-19 gün arasında olduğu bildirilmiş̧ir (Lauer et al., 2020). Bu veriler COVID-19'un inkübasyon süresinin MERS ve SARS ile benzer olduğunu ve influenzadan biraz daha uzun olduğunu göstermektedir (Bulut \& Kato, 2020). COVID-19, grip benzeri semptomlar ile ortaya çımaktadır. Semptomlar genellikle öksürük, boğaz ağrısı, ateş, kas ve vücut ağrıları şeklinde belirginleşir (CDC, 2019). Bazı vakalarda koku ve/veya tat kaybı da bildirilmiştir (Galanakis, 2020). COVID-19 hastalığı için henüz herhangi bir tedavi veya aşı geliştirilememiştir. Bu nedenle bilim camiası ve resmi kurum ve kuruluşlar, mevcut ve gelecekte olabilecek pandemik krizlerin kısa ve uzun vadeli yönetimi için çeşitli çalışmalar yürütmektedirler. Gıda sektörü ve paydaşları da yürütülen bu çalışmaların içerisinde yer almaktadır. Çünkü mevcut işgücünde $\% 25$ 'ten fazla azalmaya neden olan ciddi bir pandemi, dünya genelinde önemli derecede gida kıtlığına neden olarak gıda güvencesini tehlikeye atabilir (Huff et al., 2015). Bu nedenle mevcut tehlikelerin büyük risklere dönüşümünü engellemek için bütün paydaşlar gıda sistemine yönelik kritik tehditleri ve alınacak önlemleri hızla belirlemelidir.

Gıda endüstrisinin yeni dönemde ele alması gereken bazı önemli hususlar vardır. Bunlardan en önemlisi virüsün gida zincirinde (üreticiler, perakendeciler ve tüketiciler arasında) yayılmasını önlemek için gıda güvenliği kavramının daha da önemli hale getirilmesidir. Diğeri evlerinde karantinada olan yaklaşık bir milyar insanın gıda üretiminden çekilmesi nedeniyle gıda güvencesinde ortaya çıkabilecek problemlerin çözümüdür. Bir diğeri tüketicilerin bağ ş̧ıklık sistemlerini güçlendirmek amacıyla daha sağlıklı diyetlere yönelmesi nedeniyle, bu ürünlere olan talebin artması sonucu piyasada bu ürünlerin tedarikinde yaşanabilecek sorunların giderilmesidir. Bütün bunların yanı sıra, bu hususların çözülebilmesi ve gelecekte olabilecek olan krizlerin etkilerinin azaltılabilmesi için gıda sistemlerinin sürdürülebilirliğinin sağlanması gereklidir.

\section{Koronavirus (CoV) ve SARS-CoV-2'nin Rezervuarı}

Koronaviruslar (CoVs), evcil ve vahşi hayvanlarda ılımlı ve şiddetli olmak üzere enterik, solunum ve sistemik hastalıklara sebep olurlar. İnsanlarda da yaygın olarak 1lımlı üst solunum yolu efeksiyonları ve şiddetli alt solunum yolu efeksiyonlarına (pneumoniye) neden olur. (Hasöksüz ve ark., 2020). CoV'lar, Nidovirales ailesine ait pozitif iplikli, zarflı RNA virüsleridir ve Alfa, Beta, Delta ve Gama olmak üzere dört soya ayrılmışlardır (Wu et al., 2020). Yedi koronavirus türü insanlarda enfeksiyon oluşturur. Bunlardan dördü (HCov 229E, HCov NL63, HCoV HKU1 ve HCoV OC43) bağışıklık sistemi zayıf bireylerde üst solunum yolu semptomlarına (soğuk algınlığı) neden olurken (Hasöksüz et al., 2020), Beta-CoV'lardan olan diğer ikisi, şiddetli akut solunum sendromu (SARS-CoV) ve Orta Doğu solunum sendromuna (MERS-CoV) neden olarak dünya çapında ciddi salgınlar meydana getirmiştir (Corman et al., 2018). Aralık 2019'da da Çin'in Wuhan kentinden yeni tip CoV (SARS-CoV-2) ortaya çıkmış ve hızla küresel bir salgın halini almıştır (Wu et al., 2020). Asıl konağı tam olarak bilinmemekle birlikte, mevcut tüm veriler vahşi hayvan (yarasa) kaynağına işaret etmektedir (Zhou et al., 2020). Bu yeni tip solunum sistemi patojeni, insanları enfekte ettiği bilinen yedinci CoV'dur.

\section{SARS-CoV-2'nin Kimyasal Yapısı ve Patobiyolojisi}

Virüsler, replikasyon döngülerini 3 üç temel adımda tamamlarlar. Bunlardan ilki konakçı hücreye bağlanmadır. Daha sonra konakçı hücrenin içerisine genomik materyallerini aktarırlar ve son olarak konakçı hücre genom mekanizmaları yoluyla yeni virionlar oluştururlar (Pressman et al., 2020). CoV'ların virülensı dört yapısal proteinle ilişkilidir. Bunlar Spike (S), Zarf (Envelope-E), Membran (M) ve Nükleokapsid (N) proteinleridir (Wang et al., 2020). Bunlardan S proteini viral bağlanma, füzyon ve konak hücreye girişte kritik bir rol oynar. S proteini, reseptör bağlanma alanı (receptor-binding domain RBD) yoluyla konak reseptörüne bağlanır ve daha sonra virüs ve konak membranlarını S2 alt biriminden birleştirerek konakçı hücrelere virüs girişini sağlayan bir 'kanca'dır. Hem SARS-CoV hem de SARS-CoV-2, kan basınc1 regülasyonunda yer alan bir ekzopeptidaz olan anjiyotensin dönüştürücü enzim 2'yi (ACE2) konak bağlayıcı reseptörü olarak tanır (Pressman et al., 2020). S proteininin bu iki temel özelliği, virüsün konakçı solunum 
hücrelerine girmesine olanak sağlar. SARS-CoV-2'nin S proteinindeki RBD, virüs bağlanma inhibitörlerinin, nötralize edici antikorların ve aşıların geliştirilmesi için en olası hedeftir.

Solunum yolu mukozal epitelleri, bir müsin polisakkarit tabakası (genellikle sülfatlı bileşikler-Heparan Sülfat) ile kaplıdır. Sonuç olarak, heparan sülfat ve benzeri polisakkaritlerin CoV enfeksiyonu patobiyolojisinde rol oynadığı bildirilmiştir (Mycroft-West et al., 2020). Bununla birlikte mukozal sekresyonlara özgü laktoferrin, defensinler ve lizozim gibi antimikrobiyal proteinler, insanlar da dahil olmak üzere memeliler arasında birincil basamak savunmayı sağlamak için potansiyel bir viral yapışma engelleyici ajanlardır (Lang et al., 2011; Pressman et al., 2020). Viral bağlanma/ayrılma mekanizmalarının aydınlatılması, SARS-CoV-2'nin farklı gıda matrisleri ile etkileşimlerini anlamak ve patojeni kontrol etmek için nutrasötik besin bileşenleri geliştirmede oldukça önemlidir (Pressman et al., 2020).

\section{SARS-CoV-2'nin Bulaşma Şekli}

CoV'ların ana bulaşma şekli öksürme, hapşırma ve yüksek sesle konuşma sonucu oluşan damlacıklardır. Kişilerin birbirleri ile yakın teması bulaşma riskini arttırır (Bourouiba, 2020). Bazı çalışmalar sonucunda CoV'ların gıda yüzeyine bulaşması durumunda, optimum nem ve sıcaklığa bağlı olarak, virüsün sınırlı bir süre (birkaç saat ile birkaç gün arası) canlı kalabileceği bildirilmiştir. Buzdolabı sıcaklığında muhafaza edilen Romain maruluna deneysel olarak bulaştırılan sığır koronavirüsünün $(\mathrm{BCoV}) 25$ gün sonra dahi (canlı, enfektif) kaldıkları bildirilmiştir (Mullis et al., 2011).

İnsan ve hayvanlar arasında oldukça fazla sayıda mikroorganizma hayvandan insana ve/veya insandan hayvana bulaşarak zoonoz adı verilen birçok hastalık meydana getirirler. Zoonozlar birçok yönden (örn., ekonomik, beslenme, meslek hastalığı, halk sağlı̆̆ı) önem taşırlar. İnsanlarda görülen zoonoz hastalıkların yaklaşı \%75'inin hayvanlardan insanlara geçtiği bildirilmiştir (Taylor et al., 2001). DSÖ, özellikle az gelişmiş ve gelişmekte olan ülkelerde geçimini hayvancılık ile sağlayan insanlar arasında ihmal edilen zoonozları kontrol etmenin önemini vurgulamaktadır (Pressman et al., 2020). SARS ve kuş gribi (H5N1) gibi yeni ortaya çıan zoonozlar hariç zoonoz hastalıkların büyük çoğunluğuna, ulusal ve uluslararası düzeylerde sağlık sistemleri tarafindan öncelik verilmemekte ve bu nedenle ihmal edilmiş olarak değerlendirilmektedirler (WHO, 2020b).

CoV'lar hayvanlardan insanlara bulaşan zoonoz virüslerdir. SARS Asya ve Afrika'ya özgü yarasalar tarafindan, MERS ise develer tarafindan insanlara bulaşmıştır. SARS-CoV-2'nin yarasa ile ilişkili SARS-CoV ile benzerliği göz önüne alındığında, yarasaların rezervuar olarak görülmesi ve insanlara bulaştırması muhtemeldir (Zhou et al., 2020). Karıncayiyenlerin bulaştırdığı bazı CoV'ların SARS-CoV-2'ye benzer bir reseptör bağlanma alanı (RBD) vardır. Böylece karıncayiyenlerin de virüsün insanlara bulaşmasında doğrudan veya dolaylı olarak etkili olabileceği bildirilmiştir (Pressman et al., 2020).

Grip ve diğer solunum yolu sistemi virüsleri gibi SARS-CoV-2'de de bulaşma, kişiden kişiye bulaşma şeklindedir. Virüs, hasta kişinin hapşırmasından veya öksürmesinden sonra havada asılı kalan ve görünmez olan su damlacıkları yoluyla yayılır. Enfekte bir kişinin 1,8 metre yarıçapındaki herkes risk altındadır. RNA virüslerinin yayılması ve genetik aktarımı sıklıkla solunum ve damlacık yolu ile gerçekleştiği için, gerekli önlemler alındığ 1 takdirde SARS-CoV2'nin insandan insana bulaşma yoluyla daha az virülent olması beklenir (Pressman et al., 2020).

\section{Gıda Kaynaklı Enfeksiyon ve Bulaşma}

CoVs enfeksiyonlarının besi ve süt sı̆̆ırlarında kış dizanterisine, domuzlarda solunum yolu enfeksiyonlarına ve kümes hayvanlarında ise kuş enfeksiyoz bronşitine neden olduğu bilinmektedir. SARS ve MERS salgınlarında virüslerin hayvanlardan insanlara bulaştığı bilgisi kesindi. Mevcut COVID-19 salgınında da benzer zoonotik ilişkiden (yarasalar ve karıncayiyen 
vasitasıyla bulaşma) bahsetmek mümkündür. $\mathrm{Bu}$ nedenle SARS-CoV-2 bulaşmasında çiftlik hayvanlarının potansiyel gıda güvenliği riskini ortadan kaldırmak için daha fazla çalışmaya ihtiyaç vardır (Pressman et al., 2020).

Kırmızı et, kanatlı hayvan etleri ve deniz ürünleri SARS-CoV-2'nin konak doku epitel hücreleri ile etkileşime girmesine olanak sağlayan heparan sülfat (glikozaminoglikanlar) bakımından zengindir (Mycroft-West et al., 2020). Bu virüsün karton, plastik ve paslanmaz çelik gibi cansız yüzeylerde günlerce canlı kaldığı düşünüldüğünde, hayvansal dokuların COVID-19'un gıda kaynaklı iletimi için kritik olabileceğini göstermektedir (van Doremalen et al., 2020). COVID19'un gıda ve gıda işleme yoluyla insanlara bulaşma olasılığını değerlendirmek için ek çalışmalar yapılması gerekmektedir.

\section{Gıda Kontaminasyonu ve Gıdalarda Yaşaması}

Norovirüs ve Hepatit-A gibi enterik virüsler gida ekipmanlarının yüzeylerinde haftalarca hayatta kalabilir ve yüksek sıcaklıklara dayanıklıdırlar. Bu özellikleri nedeniyle gıdaları kolayca kontamine edebilirler. COVID-19 ise yüzeylerde uzun süre canlılığını koruyamaz. Ayrıca bakterilerin aksine, virüsler gıdalarda çoğalamaz. Çünkü virüsleri çoğalabilmesi için canlı hücreye ihtiyacı vardır. Bu nedenle cansız yüzeylerdeki viral yükün zamanla azalması beklenir.

Yapılan 22 farklı araştırmanın sonucunda, insan CoV'larının metal, cam veya plastik gibi cansız yüzeylerde 9 güne kadar canlı kalabileceği bildirilmiştir. Yüzey dezenfeksiyonunda 1 dakikalık süre ile $\% 0.1$ 'lik sodyum hipoklorit, $\% 0.5$ 'lik hidrojen peroksit veya $\% 62-71^{\prime}$ 'lik etanol kullanılmasının CoVs enfeksiyon riskini önemli ölçüde azaltabileceği bildirilmiştir. $\mathrm{Bu}$ dezenfektanların SARS-CoV-2'ye de benzer bir etki göstermesi beklenmektedir (Kampf et al., 2020). Güncel tarihli bir çalışmada, SARS-CoV-2'nin havada 3 saat, bakır materyaller üzerinde 4 saat, kartonda 24 saat, plastik ve paslanmaz çelikte 72 saat canlı kalabildiği bildirilmiştir (van Doremalen et al., 2020).

Ayrıca SARS-CoV, ultraviyole 1şık, yüksek sıcaklık ( $\left.>65^{\circ} \mathrm{C}\right)$, alkalin $\mathrm{pH}(>12)$ veya asidik pH'ya $(<3)$ maruz kaldığında etkisiz hale gelebilir (Darnell et al., 2004). Tüm bu veriler, kontamine olmuş bir gıdanın SARS-CoV-2'yi insanlara bulaştırma riskini en aza indirmek için, gıdaların pişirilmesi veya işlenmesinin önemini vurgulamaktadır.

Gıda işleme sırasında SARS-CoV-2'nin kontamine yüzeylerden işletme personelinin ellerine bulaşması mümkündür. Kişi, kontamine bir yüzeye veya nesneye dokunduğunda SARSCoV-2'ye maruz kalabilir ve sonrasinda oral, nazal veya optik yollarla kendi kendini enfekte edebilir. Bazı bireyler oral yolla enfekte olsalar da SARS-CoV-2 oldukça 'duyarlı' bir virüstür. Teorik olarak, yutulan SARS-CoV-2 mide asidiyle tahrip edilir. Sabunla ellerin yıkanması ve/veya alkol bazlı el dezenfektanlarının kullanılması ile kolayca elimine edilebilir. Proaktif bir yaklaşım olarak, gıda kaynaklı hastalıkları (COVID-19 da dahil) önlemek için gıda güvenliğinin 4 adımı (temizle, ayıkla, pişir ve soğut) etkin bir şekilde uygulanmalıdır (Pressman et al., 2020).

\section{Risk Yönetimi ve Gelecek Dönem Yaklaşımları}

Risk yönetimi; tehlikelerden doğabilecek risklerin belirlenmesi ve bunların ortaya çıkışını önlemeye, zararları oluşmadan bertaraf etmeye yönelik bir erken uyarı sistemidir (Uslu, 2016). Risk yönetimi göz önüne alındığında, CDC, USDA ve Avrupa Gıda Güvenliği Otoritesi (EFSA), COVID-19'un gıda veya gıda ambalajı yoluyla bulaştığını destekleyecek kanıt bulunmadığını bildirmiştir (FDA, 2020). Önceki CoVs salgınlarında da benzer şekilde gıda veya gıda ambalajı yoluyla bulaşma ile ilgili bir kanıt gösterilememiştir. Bununla birlikte, bu sonuçlar enfeksiyöz virionların gastrointestinal sisteme ulaştığını ve böylece SARS-CoV-2'nin fekal-oral bulaşma olasılığını da düşündürmektedir. Bu durum ayrıca COVID-19 enfeksiyonlarına karşı korunmada kişisel hijyen ve sanitasyon kurallarının önemini ortaya koymaktadır. 


\section{Sonuç}

Virüs epidemiyolojisi oldukça karmaşıtır. Koronavirüsler hayvan rezervuarlarından insan konaklarına yayılabilir. Türler arasındaki bu bulaşma için kesin mekanizma tam olarak anlaşılamamıştır. Ancak evcil veya vahşi hayvanların ve insanların neredeyse iç içe olduğu kalabalık ortamlarda hayvanlardan insanlara hastalık bulaşması çok sık ortaya çıkmaktadır. Ortaya çıkan veriler öksürme ve hapşırma sonucu oluşan damlacıklarla meydana gelen inhalasyon bulaşmaya ek olarak, fekal-oral yayılımın dikkatlice kontrol edilmesi ve izlenmesi gerektiğini göstermektedir.

Dünyada salgın dönemlerinde gıda zincirinin güvenliği daha da önem kazanmaktadır. Salgına neden olan etkenin bu zincire bulaşmaması ve zincirin kırılmaması oldukça önemlidir. Dünyayı tehdit eden COVID-19 hastalığı, solunum ve temas yoluyla insanlara SARS-CoV-2'nin geçmesi ile ortaya çıkmış bir hastalıktır. Mevcut çalışmalara göre bu virüsün gıdaları kontamine etmesi, gıda işletmelerinde çalışan ve hastalık belirtisi göstermeyen ancak virüsü taşıyan enfekte gıda çalışanlarının gıdaları bulaştırması şeklinde olmaktadır. Bu nedenle gıda zincirinde çalışan personelin, COVID-19 dahil diğer tüm gida güvenliği tehlikeleri hakkında bilinçlendirilmesi, hasta olanların çalıştırılmaması ve maske takması zorunluluk arz etmektedir.

Mevcut çalışmalara göre SARS-CoV-2 virüsünün gıda ve gıda ambalajı ile bulaştığına dair herhangi bir bilgi bulunmamakla birlikte enfekte kişilerin, gıda ve gıda ambalajları ile teması olabileceği ihtimali düşünülmeli ve bu amaçla kişisel hijyen sağlanmalıdır. Gıdaların tüketiminden önce rutin gıda güvenliği uygulamalarına dikkat edilmeli ve uygulanmalıdır. En önemli uygulama ise herhangi bir yüzeye veya gıdaya temastan sonra ellere, ağız, burun veya gözlere dokunulmamalıdır. Eller mutlaka en az 20 saniye olacak şekilde su ve sabunla yıkanmalıdır. Bu süreçte tüketicilerin de büyük sorumlulukları vardır. Tüketiciler gıda alış-verişlerini yaparken sosyal mesafeyi korumalı, maske takmalı ve genel hijyen kurallarına dikkat etmelidir. Market alışverişi sonrası, alınan ürünlerden yıkanabilir olanların sabunlu su ile yıkanması, yıkanamaz olanların ise bir süre uygun ortamlarda bekletildikten sonra kullanılmasına dikkat edilmelidir. Pişirilerek tüketilmesi gereken gıdalar, çiğ ya da az pişmiş olarak tüketilmemelidir. Çapraz kontaminasyonu önlemek için çiğ ve pişmiş ürünler bir arada işlenmemeli ve tutulmamalıdır. Çiğ tüketilen meyve ve sebzeler ise tüketilmeden önce bol su ve gıda temizleme firçaları ile iyice yıkanmalıdır.

Sonuç olarak SARS-CoV-2'nin neden olduğu COVID-19 hastalığı halk sağlığı için büyük bir risk oluşturmaktadır. Her ne kadar gıdaların tüketilmesiyle bu virüsün bulaştığına dair günümüze kadar bilimsel bir veri bulunmasa da gıda üreticileri ve tüketicilerin hijyen kurallarına her zamankinden daha fazla uyması ve günlük hayatlarında hijyen kurallarını rutin bir işleme çevirmeleri gerekmektedir. Böylelikle bu virüsün gıdalarla taşınması konusundaki endişelerin ve dolayısıyla tartışmaların önüne geçilebileceği düşünülmektedir.

\section{Kaynakça}

Bulut, C., \& Kato, Y. (2020). Epidemiology of covid-19. Turkish Journal of Medical Sciences, 50(SI-1), 563-570. https://doi.org/10.3906/sag-2004-172

Bourouiba, L. (2020). Turbulent Gas Clouds and Respiratory Pathogen Emissions: Potential Implications for Reducing Transmission of COVID-19. In JAMA - Journal of the American Medical Association (Vol. 323, Issue 18, pp. E1-E2). American Medical Association. https://doi.org/10.1001/jama.2020.4756

CDC. (2019). How Coronavirus Spreads | CDC. https://www.cdc.gov/coronavirus/2019ncov/prevent-getting-sick/how-covid-

spreads.html?CDC_AA_refVal=https\%3A\%2F\%2Fwww.cdc.gov\%2Fcoronavirus\%2F201 
9-ncov\%2Fprepare\%2Ftransmission.html

Corman, V. M., Muth, D., Niemeyer, D., \& Drosten, C. (2018). Hosts and Sources of Endemic Human Coronaviruses. In Advances in Virus Research (Vol. 100, pp. 163-188). Academic Press Inc. https://doi.org/10.1016/bs.aivir.2018.01.001

Darnell, M. E. R., Subbarao, K., Feinstone, S. M., \& Taylor, D. R. (2004). Inactivation of the coronavirus that induces severe acute respiratory syndrome, SARS-CoV. Journal of Virological Methods, 121(1), 85-91. https://doi.org/10.1016/j.jviromet.2004.06.006

FDA. (2020). Food Safety and the Coronavirus Disease 2019 (COVID-19) I FDA. https://www.fda.gov/food/food-safety-during-emergencies/food-safety-and-coronavirusdisease-2019-covid-19

Galanakis, C. M. (2020). The Food Systems in the Era of the Coronavirus. Foods, 9(4), 1-10.

Hasöksüz, M., Kiliç, S., \& Saraç, F. (2020). Coronaviruses and sars-cov-2. Turkish Journal of Medical Sciences, 50(SI-1), 549-556. https://doi.org/10.3906/sag-2004-127

Huff, A. G., Beyeler, W. E., Kelley, N. S., \& McNitt, J. A. (2015). How resilient is the United States' food system to pandemics? Journal of Environmental Studies and Sciences, 5(3), 337-347. https://doi.org/10.1007/s13412-015-0275-3

Kampf, G., Todt, D., Pfaender, S., \& Steinmann, E. (2020). Persistence of coronaviruses on inanimate surfaces and their inactivation with biocidal agents. In Journal of Hospital Infection, 104(3), 246-251). https://doi.org/10.1016/j.jhin.2020.01.022

Lang, J., Yang, N., Deng, J., Liu, K., Yang, P., Zhang, G., \& Jiang, C. (2011). Inhibition of SARS pseudovirus cell entry by lactoferrin binding to heparan sulfate proteoglycans. PLoS ONE, 6(8). https://doi.org/10.1371/journal.pone.0023710

Lauer, S. A., Grantz, K. H., Bi, Q., Jones, F. K., Zheng, Q., Meredith, H. R., Azman, A. S., Reich, N. G., \& Lessler, J. (2020). The incubation period of coronavirus disease 2019 (CoVID-19) from publicly reported confirmed cases: Estimation and application. Annals of Internal Medicine, 172(9), 577-582. https://doi.org/10.7326/M20-0504

Li, Q., Guan, X., Wu, P., Wang, X., Zhou, L., Tong, Y., Ren, R., Leung, K. S. M., Lau, E. H. Y., Wong, J. Y., Xing, X., Xiang, N., Wu, Y., Li, C., Chen, Q., Li, D., Liu, T., Zhao, J., Liu, M., Feng, Z. (2020). Early transmission dynamics in Wuhan, China, of novel coronavirusinfected pneumonia. New England Journal of Medicine, 382(13), 1199-1207. https://doi.org/10.1056/NEJMoa2001316

Mullis, L., Saif, L. J., Zhang, Y., Zhang, X., \& Azevedo, M. S. P. (2011). Stability of bovine coronavirus on lettuce surfaces under household refrigeration conditions. Food Microbiology, 30, 180-186. https://doi.org/10.1016/j.fm.2011.12.009

Mycroft-West, C. J., Su, D., Elli, S., Guimond, S. E., Miller, G. J., Turnbull, J. E., Yates, E. A., Guerrini, M., Fernig, D. G., Lima, M. A. de, \& Skidmore, M. A. (2020). The 2019 coronavirus (SARS-CoV-2) surface protein (Spike) S1 Receptor Binding Domain undergoes conformational change upon heparin binding. BioRxiv, 2020.02.29.971093. https://doi.org/10.1101/2020.02.29.971093

Pressman, P., Naidu, A. S., \& Clemens, R. (2020). COVID-19 and Food Safety. Nutrition Today, 55(3), 125-128. https://doi.org/10.1097/NT.0000000000000415

Taylor, L. H., Latham, S. M., \& Woolhouse, M. E. J. (2001). Risk factors for human disease emergence. Philosophical Transactions of the Royal Society B: Biological Sciences, 356(1411), 983-989. https://doi.org/10.1098/rstb.2001.0888 
Uslu, M. K. (2016). Laboratuvar çalişanlarinin karşilaştiği fiziksel risklerin hata türü ve etkileri analizi(Htea) ile değerlendirilmesi: bir üniversite hastanesi örneği. Selçuk Üniversitesi Sağlık Bilimleri Enstitüsü.

van Doremalen, N., Bushmaker, T., Morris, D. H., Holbrook, M. G., Gamble, A., Williamson, B. N., Tamin, A., Harcourt, J. L., Thornburg, N. J., Gerber, S. I., Lloyd-Smith, J. O., De Wit, E., \& Munster, V. J. (2020). Aerosol and surface stability of SARS-CoV-2 as compared with SARS-CoV-1. New England Journal of Medicine, 382(16), 1564-1567. https://doi.org/10.1056/NEJMc2004973

Wang, N., Shang, J., Jiang, S., \& Du, L. (2020). Subunit Vaccines Against Emerging Pathogenic Human Coronaviruses. In Frontiers in Microbiology (Vol. 11). Frontiers Media S.A. https://doi.org/10.3389/fmicb.2020.00298

WHO. (2020a). Director-General's Opening Remarks at the Media Briefing on COVID-19- 11 March 2020. https://www.who.int/dg/speeches/detail/who-director-general-s-openingremarks-at-the-mediabriefing-\%0Aon-covid-19-11-march-2020

WHO. (2020b). Neglected zoonotic diseases. https://www.who.int/neglected_diseases/diseases/zoonoses/en/

Wu, F., Zhao, S., Yu, B., Chen, Y. M., Wang, W., Song, Z. G., Hu, Y., Tao, Z. W., Tian, J. H., Pei, Y. Y., Yuan, M. L., Zhang, Y. L., Dai, F. H., Liu, Y., Wang, Q. M., Zheng, J. J., Xu, L., Holmes, E. C., \& Zhang, Y. Z. (2020). A new coronavirus associated with human respiratory disease in China. Nature, 579(7798), 265-269. https://doi.org/10.1038/s41586020-2008-3

Zhou, P., Yang, X. Lou, Wang, X. G., Hu, B., Zhang, L., Zhang, W., Si, H. R., Zhu, Y., Li, B., Huang, C. L., Chen, H. D., Chen, J., Luo, Y., Guo, H., Jiang, R. Di, Liu, M. Q., Chen, Y., Shen, X. R., Wang, X., Shi, Z. L. (2020). A pneumonia outbreak associated with a new coronavirus of probable bat origin. Nature, 579(7798), 270-273. https://doi.org/10.1038/s41586-020-2012-7 